BMJ

Open

Gastroenterology

\title{
Intestinal stem cells promote crypt fission during postnatal growth of the small intestine
}

\author{
Zenab Mustansir Dudhwala (D) , ${ }^{1,2}$ Paul D Hammond, ${ }^{3}$ Gordon S Howarth, ${ }^{3,4}$ \\ Adrian Gerard Cummins ${ }^{2,5}$
}

To cite: Dudhwala ZM, Hammond PD, Howarth GS, et al. Intestinal stem cells promote crypt fission during postnatal growth of the small intestine. BMJ Open Gastro 2020;7:e000388. doi:10.1136/ bmjgast-2020-000388

Received 14 February 2020 Revised 21 April 2020 Accepted 24 April 2020
Check for updates

(C) Author(s) (or their employer(s)) 2020. Re-use permitted under CC BY-NC. No commercial re-use. See rights and permissions. Published by BMJ.

${ }^{1}$ Gastroenterology, Basil Hetzel Institute for Translational Health Research, Woodville South, South Australia, Australia

${ }^{2}$ Surgery, The University of Adelaide - North Terrace Campus, Adelaide, South Australia, Australia ${ }^{3}$ Gastroenterology, Women's and Children's Hospital

Adelaide, North Adelaide, South Australia, Australia

${ }^{4}$ Animal and Veterinary Sciences, The University of Adelaide, Adelaide, South Australia, Australia

${ }^{5}$ Gastroenterology, Basil Hetzel Institute for Medical Research, Woodville South, South Australia, Australia

Correspondence to Dr Zenab Mustansir Dudhwala; zenab.dudhwala@adelaide. edu.au

\begin{abstract}
Objective Wnt- $\beta$-catenin signalling is essential for intestinal stem cells. Our aim was to investigate the relationship between intestinal stem cells and crypt fission which peaks during infancy.

Design Duodenal biopsies were obtained during endoscopy to assess the severity of reflux oesophagitis of 15 infants, children and teenagers, which would not affect the duodenum. Samples of small intestine were also obtained from rats 7-72 days of life. Crypt fission was assessed using microdissection of 100 whole crypts and recording the percentage of bifid crypts. Intestinal LGR5+ stem cells were identified by in situ hybridisation. Rats were treated with Dickkopf to block Wnt- $\beta$-catenin signalling.

Results Crypt fission peaked during infancy before declining after 3-4 years in humans and after 21 days of life in rats. Occasional mitotic figures were seen in bifid crypts during early fission. Stem cells were elevated for a greater period during infancy and childhood in humans. Clustering of Paneth cells was present around the stem cells at the crypt base. Dickkopf reduced the number of stem cells and crypt fission to $45 \%$ and $29 \%$, respectively, of control values, showing dependence of both crypt fission and Lgr5+ stem cells on Wnt signalling. However, Dickkopf did not decrease mitotic count per crypt, indicating a difference in signalling between stem cells and their progeny in the transit amplifying zone. Conclusion Crypt fission peaks during infancy and is dependent on intestinal stem cells. This is relatively hidden by 'a cloak of invisibility' due to the low proliferation of stem cells.
\end{abstract}

\section{INTRODUCTION}

Intestinal crypt fission is the process of longitudinal division of a crypt into two daughter crypts (figure 1). The process begins at the crypt base. ${ }^{1-4}$ Crypt fission occurs physiologically during postnatal growth in mice, ${ }^{1-3}$ rats, ${ }^{4-6}$ pigs $^{7}$ and humans. ${ }^{8}$ It also occurs pathologically in rodents and humans with the APC mutation, ${ }^{9}$ in response to cytotoxic drugs and mutagens, ${ }^{10} 11$ during repair after irradiation, ${ }^{12}$ or in response to surgical resection. ${ }^{13}$ Crypt fission is a separate but complementary process to crypt hyperplasia
Summary box

What is already known about this subject?

- Crypt fission increases growth of the small intestine in mice and rats.

What are the new findings?

- LGR5+ intestinal stem cells were expanded in both rats and humans during infancy.

- Expansion of intestinal stem cells occurred through division of whole crypts, but was 'hidden'.

- Intestinal stem cells remained elevated in humans until mid-teenage years, but declined rapidly in infant rats.

- Blockade of Wnt signalling with Dickkopf (a specific Wnt inhibitor) in rats reduced both intestinal stem cells and crypt fission, but did not affect mitotic count per crypt.

How might it impact on clinical practice in the foreseeable future?

- Trials of intestinal growth factors for intestinal failure should adequately assess crypt fission and intestinal stem cells, as most studies have only investigated factors/hormones augmenting crypt hyperplasia.

for intestinal epithelial growth. ${ }^{6}$ Studies of hormone growth factors (eg, insulinlike growth factor I or II, epidermal growth factor, keratinocyte growth factor) have not examined crypt fission, only crypt hyperplasia. ${ }^{1415}$ Crypt fission broadens the primary cylindrical surface, whereas crypt hyperplasia grows inwards (orthogonally) to enlarge the secondary mucosal surface. ${ }^{16}$

Crypt fission is initiated in the stem cell region at the base of the crypts. ${ }^{17}$ Here, there are alternating stem cells and differentiated Paneth cells in close apposition, making up the stem cell niche (figure 1A). ${ }^{18}$ Later, the idea of a stem cell niche was expanded to include the surrounding pericryptal stroma. ${ }^{19}$ Intestinal stem cells were initially termed 'crypt base columnar cells'. ${ }^{1}$ They are slender cells with vertical nuclei and sparse cytoplasm intercalated between Paneth 

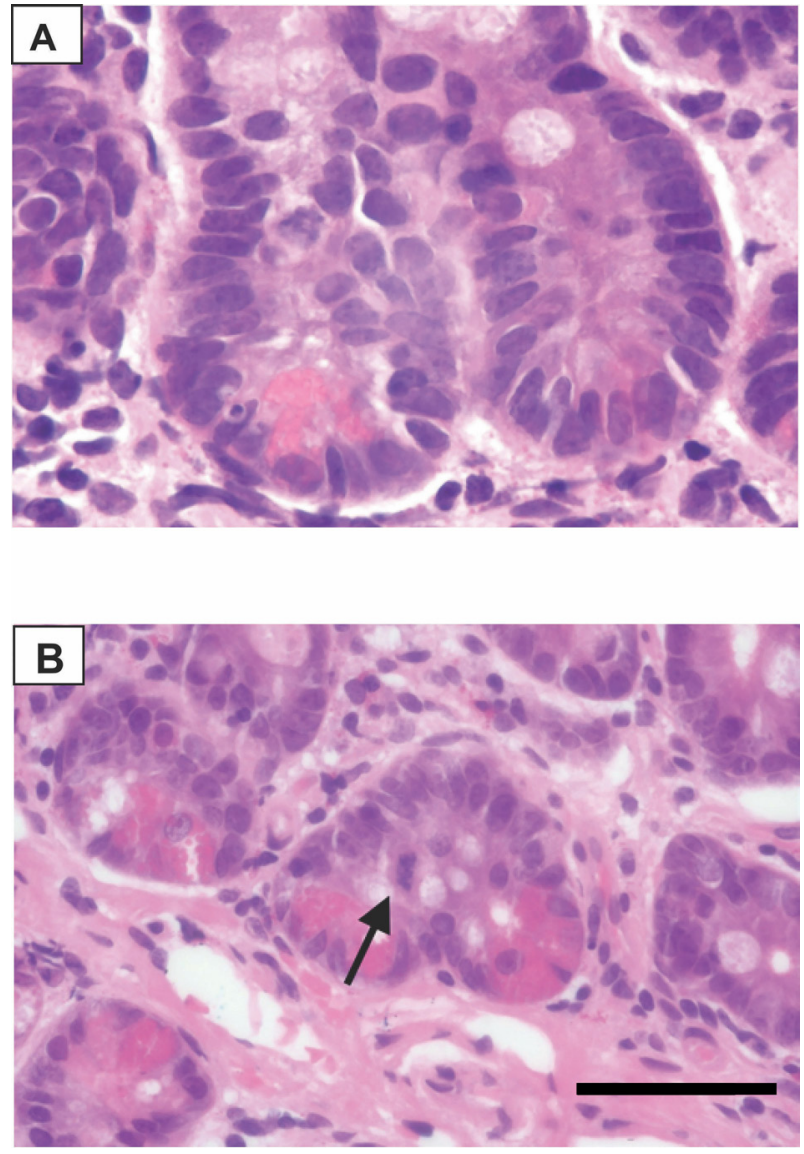

Figure 1 (A) The lower region of a crypt is shown with the upper segment not in the plane of section. The crypt base is populated by pink Paneth cells and alternating slender crypt base columnar (CBC) cells. (B) A bifid crypt with a cluster of pink Paneth cells at the crypt base and which is indented by a CBC (arrow) which is undergoing mitosis. Bar $=50 \mu \mathrm{m}$.

cells. ${ }^{1}$ Intestinal stem cells are now identified by exclusive surface markers, such as leucine-rich repeat-containing G-protein coupled receptors (LGR5). ${ }^{20}$ Wnt- $\beta$-signalling is essential for maintenance of adult intestinal stem cells, ${ }^{21}$ although how this occurs is not well defined. LGR5 is the receptor for R-spondins 1-4, which prolong the action of Wnt3 and Wnt2b, which are ligands for Wnt- $\beta$-signalling in the intestinal crypt. ${ }^{22-24}$ Stem cells are mitotically active but have slower proliferation than their more mitotically active progeny in the transit amplifying cell zone. The cycle time of stem cells is 21-24hours in mice..$^{2025}$ This contrasts with the rapid proliferation of transit amplifying cells, which have a cell cycle time of 12 hours.

A doubling of stem cells in the base of the crypt was initially suggested as the initial event in crypt fission. ${ }^{26} 27$ This has not been observed in vivo in mice. ${ }^{3}$ Later, a further mechanism was advanced with formation of a cluster of Paneth cells around a stem cell, creating a nidus of weakness that indents at the leading edge of the stem cell. ${ }^{28} 29$ This is supported by budding of intestinal organoids in culture and in mice. ${ }^{28}$

The aims of this study were to investigate the age dependence of crypt fission using a tissue microdissection technique in humans and rats, and to investigate the relationship between expansion of intestinal stem cells and promotion of crypt fission.

\section{SUBJECTS, ANIMALS AND METHODS Subjects}

Subjects were recruited after being booked for endoscopy for medical reasons, typically to investigate the severity of reflux oesophagitis or dyspepsia for exclusion of duodenal ulcers. Biopsies for research were only taken if there is no macroscopic duodenal ulcer disease. The research component was to collect four additional biopsies from the second/third segment of the duodenum. There were 15 subjects and 16 sets of biopsies at age intervals (one child had two endoscopies a few months apart). Two subjects were siblings. The age range was 1.1-14.7 years. Infants were defined as older than 4 weeks but less than 2 years. Biopsies were collected in Clarke's fixative $\left(75 \% \mathrm{v} / \mathrm{v}\right.$ and $25 \% \mathrm{v} / \mathrm{v}$ glacial acetic acid $\left.{ }^{4}\right)$ and neutral buffered formalin. The values of crypt fission in a further 13 infants, 16 children and 39 adults from a previous study were combined with those in the present study. ${ }^{8}$

\section{Rats}

Rats in litters were killed at 7, 14, 21, 28, 35 and 72 days of life. The small intestine was removed and $1 \mathrm{~cm}$ samples taken at one-third along the length from the pylorus. Samples were shaken in Clarke's fixative and placed in neutral buffered formalin overnight. The next day, the Clarke's fixative and formalin were decanted and replaced with $70 \% \mathrm{vol} / \mathrm{vol}$ ethanol for storage until processed.

\section{Assessment of crypt fission by microdissection}

Crypt fission was evaluated by a microdissection technique to isolate whole crypts. ${ }^{30-33} \mathrm{~A}$ small portion, approximately $3 \times 2 \mathrm{~mm}^{2}$, was rehydrated and heated in $1 \mathrm{~N} \mathrm{HCl}$ at $60^{\circ} \mathrm{C}$ for $6-7 \mathrm{~min}$. Schiff's Feulgen reagent was added for about 10-30 min. The biopsy was washed in water. Tissue was placed in the lid of a Petri dish in water and microdissected with a cataract knife. Fragments of a row of villi with attached crypts (each villus has approximately 5-7 attached crypts) were carefully placed in water on a microscope slide, and this was drained with a tissue and placed in a drop of $45 \% \mathrm{v} / \mathrm{v}$ acetic acid. A coverslip was placed on top. Crypt fission was assessed by counting the number of bifid crypts and was expressed as a percentage. At least 100-200 crypts were counted. The percentage of bifid crypts was recorded. Reproducibility was assessed by repeating the microdissection on a subsequent day. The difference of the two means over the first determination was expressed as a percentage. We also compared assessment of crypt fission by branching of crypts in histological section.

\section{Crypt cell apoptosis}

During microdissection of human biopsies, the number of apoptotic cell bodies was recorded. Apoptotic cell 
bodies were recognised as dark condensed bodies often surrounded by a clear halo. They were counted in whole crypts after the tissue was squashed to separate the individual crypts.

\section{Crypt cell mitosis}

Sections of duodenum from humans were prepared and mounted onto Superfrost Plus slides for immunohistochemistry (IHC). IHC for mitotic marker Ki-67 was performed using an automated machine (Autostainer Plus, Dako, Denmark) using Dako reagents and following standard protocols supplied by the manufacturer (FLEX Plus Detection System, Dako). Briefly, sections were deparaffinised in histolene, rehydrated through graded ethanols and treated in Dako PT Link (pretreated module) with preheated $\left(65^{\circ} \mathrm{C}\right)$ FLEX Tris/EDTA at $\mathrm{pH} 9$ retrieval solution, until solution reached $97^{\circ} \mathrm{C}$ where it stayed for $20 \mathrm{~min}$. It was then cooled back down to $65^{\circ} \mathrm{C}$ and dipped into the Dako wash buffer. Non-specific staining was blocked by $100 \mu \mathrm{L}$ FLEX Peroxidase Block and $100 \mu \mathrm{L}$ serum-free protein block. Primary antibody (ab16667) was diluted in Dako antibody diluent and remained for $60 \mathrm{~min}$, followed by application of $100 \mu \mathrm{L}$ of the EnVision FLEX+Rabbit LINKER (\#K8019, Dako) and $150 \mu \mathrm{L}$ of diaminobenzidine (DAB) for $10 \mathrm{~min}$. Sections were counterstained with Lillie-Mayer's haematoxylin, dehydrated, cleared and coverslipped. Archived colon tumour sections were used as the positive control. Omission of the primary antibody was used as the negative control.

\section{LGR5+ stem cells by in situ RNA hybridisation}

RNA expression of LGR5 (intestinal stem cell marker) was assessed by in situ hybridisation of duodenal biopsies from infants, children and teenagers/adults using RNAscope 2.5 HD Reagent Kit (322300, Advanced Cell Diagnostics, Hayward, California), and probes for human LGR5 (311021, 20 pairs of specific probes, target region 560-1589) and rat LGR5 (403731, 20 pairs of specific probes, target region 200-1245) were used according to the manufacturer's instructions. A probe set for Rn-Ppib was used as the positive control. Briefly, the sections were pretreated by target retrieval reagents and incubated with the target probes for 2 hours at $40^{\circ} \mathrm{C}$. The slides were washed at room temperature after each hybridisation step using the wash buffer. DAB was used to detect positive staining. The slides were then counterstained by Gill's haematoxylin.

\section{Effect of Dickkopf on LGR5+ stem cells and crypt fission in the rat}

We retrieved paraffin blocks of small intestine from storage of saline injected control $(n=5)$ and Dickkopftreated $(n=5)$ rats from a previous study. ${ }^{34}$ Treatment was with recombinant Dickkopf at a dose of $100 \mathrm{ng}$ subcutaneously daily for 5 days. Rats were killed at 16 days of life. LGR5+ cells were identified by in situ hybridisation. Crypt fission was assessed by histological branching.

\section{Human and animal ethics}

Consent was obtained from parents and, if age appropriate, from subjects. For in situ hybridisation, we also used an archive of duodenal biopsies from adults that had been collected for previous research studies. Subject consent at the time included use of biopsies for future human research studies.

\section{Statistics}

Crypt fission in humans was plotted as individual data. In rats, data were plotted as the mean and individual datum points to record central tendency and variability. A linear regression model with continuous variables was used for human data to test departure from equivalence of crypt fission with age. A linear regression model with categorical variables was used for rats. Data were plotted using Prism V.7.0 (GraphPad Software, San Diego, USA).

\section{RESULTS}

\section{Intestinal crypt fission}

\section{Humans}

Intestinal crypt fission for humans is illustrated in figures 1 and 2A. In humans, crypt fission peaked at $\sim 27 \%$ of crypts of three infants in the present study and decreased initially quickly and then more slowly during childhood and teenage years. As there were only three infants in the present study, crypt fission data for a further 13 infants from our previous study were employed. ${ }^{8}$ The mean crypt fission in the combined total of 16 infants was $18 \%$. Reproducibility of crypt fission was confirmed by the microdissection technique, whereby the mean of a second set of measures performed the following day was within $8 \%$ of the first determination. Crypt fission was high in infants $(\sim 18 \%)$ compared with any other age groups. Comparing humans and rats, the peak of crypt fission in humans is precocious, as crypt fission in humans starts in utero from the second trimester, but perinatally in rats. ${ }^{16}$

Assessment of crypt fission by branching in histological sections gave a fivefold lower mean value of $5.1 \%$ (range: 3.7-6.5) in three infants and corresponding lower values in children and teenagers (data not shown). The mean (range) values for five teenagers aged 12 years or older was 1.5 (0-3.0). In fact, it was relatively infrequent.

\section{Rats}

Intestinal crypt fission for rats is shown in figure 2B. In rats, intestinal crypt fission peaked at $12 \%$ in 14-day-old rat pups. The same basic pattern of elevated crypt fission during infancy and decline thereafter as in humans was seen. The intensity of expression in infant rats 7 and 14 days old was high and declined thereafter, until it was just discernible in adult rats.

\section{Intestinal LGR5+ stem cells}

\section{Humans}

Intestinal stem cells per crypt are shown in figures $3 \mathrm{~A}$ and 4A. LGR5 + cells per crypt peaked broadly in infants, 
A
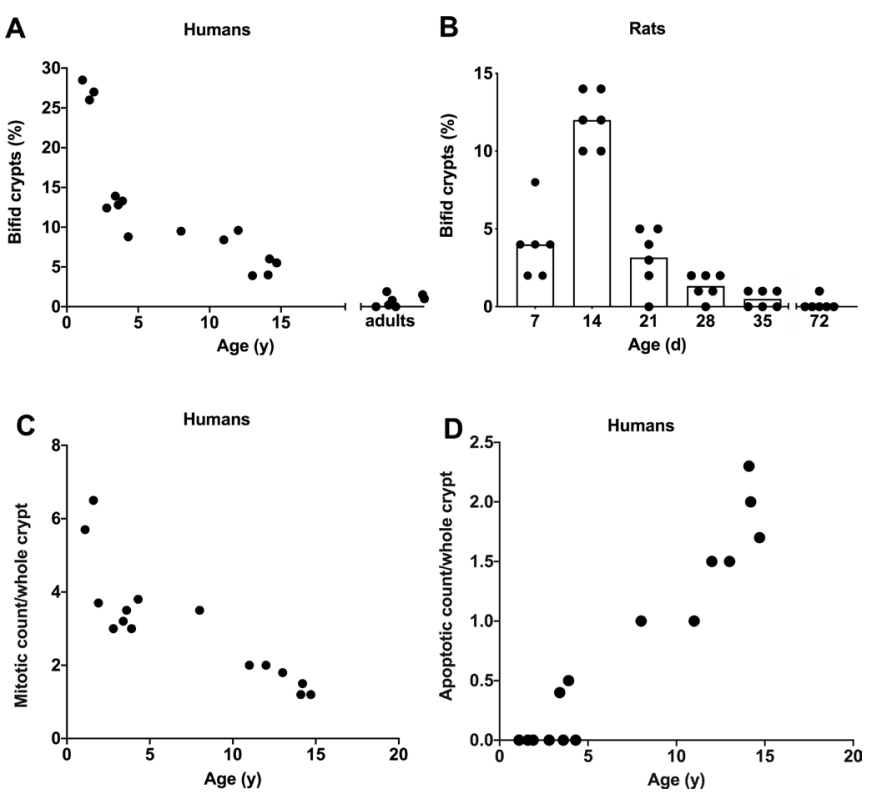

Figure 2 Age dependence of intestinal crypt fission was examined in (A) 15 infants, children and teenagers/adults, and $(B)$ rats in litters of $7,14,21,28,35$ and 72 days of life.

(A) Crypt fission as a percentage of bifid crypts on the $y$ axis versus age on the $x$ axis. Crypt fission was enumerated as the number of bifid crypts in a total of 100-150 whole crypts for each individual. (B) Percentage of bifid crypts versus age in rats. Crypt fission was high during infancy and declined during childhood in humans and young rats. Statistical analysis was performed using linear regression model in (A), and for both humans and rats crypt fission peaked during infancy (linear regression, $p<0.001$ ). (C) Mitotic count per crypt (continuous linear regression, $p<0.0001$ ) and (D) apoptotic count (continuous linear regression, $p<0.0001$ ) per crypt in humans. Mitotic count was high during infancy and decreased throughout childhood. In contrast, apoptotic count was zero until 3 years of age and increased exponentially during childhood.

children, and teenagers but were low in adults (continuous linear regression). Similarly, the intensity of expression of LGR5 was high in infants and children and was low
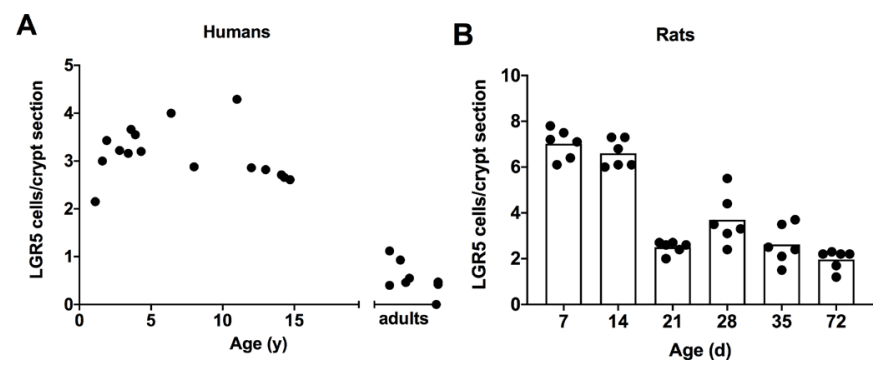

Figure 3 LGR5+ cells were identified by in situ hybridisation in (A) humans and (B) rats. LGR5+ cells are apparent in the base of the crypts between Paneth cells. LGR5 cells in humans remained elevated until the age of 15 before declining to adult values (continuous linear regression, $\mathrm{p}<0.001$ ). For rats, LGR5+ cells declined earlier in ontogeny after day 14 of life (categorical linear regression, $p<0.01$ ). LGR5, leucine-rich repeat-containing G-protein coupled receptors.
A
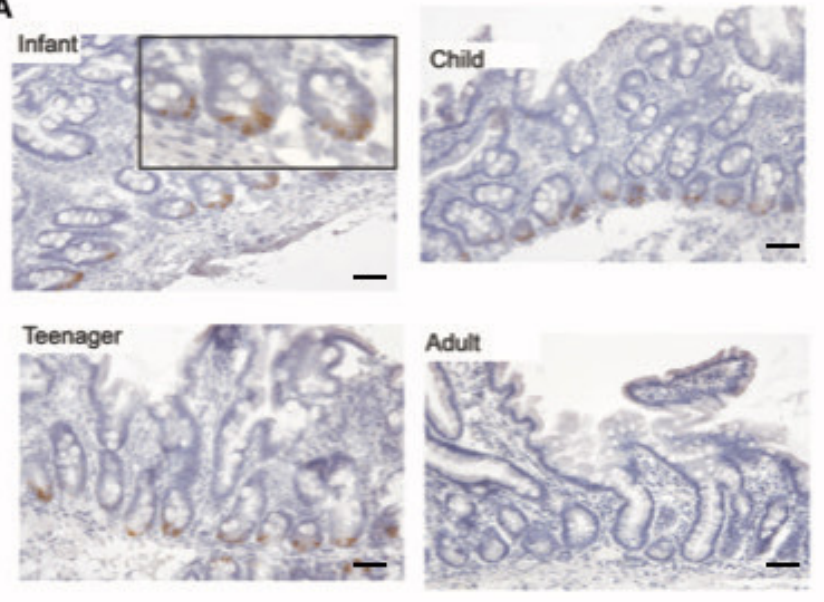

B
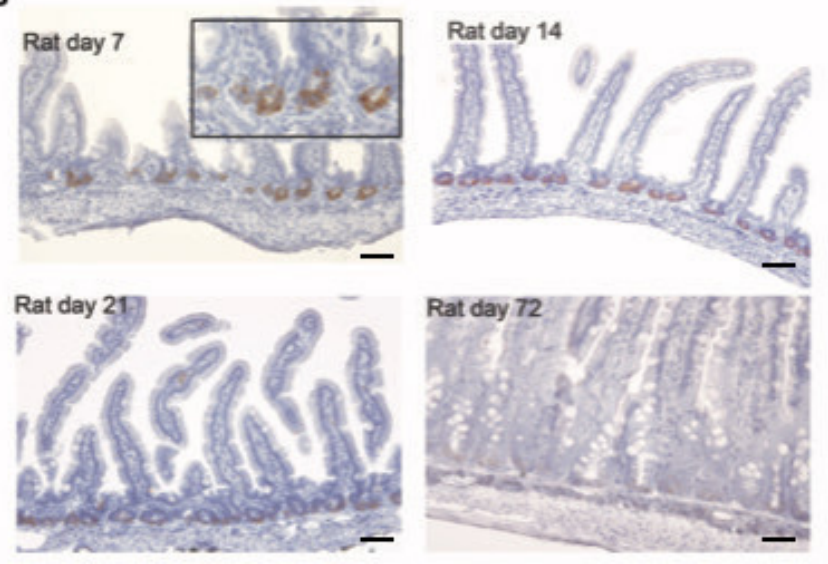

Figure 4 Representative LGR5 expressions are given for intestinal crypts of (A) humans and (B) rats. RNA expression was high in humans during infancy and early childhood, but noticeably became scarce after 15 years of age. In rats, LGR5 expression was high from 7 to 14 days and decreased markedly at 21 days and was low thereafter in rats 28 days and older. Bar=50 $\mu \mathrm{m}$. Inset boxes x2. LGR5, leucine-rich repeat-containing G-protein coupled receptors.

in adults. The intensity of LGR5 expressions in humans was less than that for rats.

Rats

LGR5 expression for rats is shown in figures 3B and 4B. The number and intensity of LGR5+ expressing cells peaked in rats 7 and 14 days old, declined to moderate levels in animals 21 days old and was lightly expressed thereafter (categorical linear regression).

\section{Mitotic count per crypt and apoptotic body count per crypt Humans}

Only occasional Ki67+ cells were present in the crypt base (cell positions 1-4). Similarly, only occasional mitotic figures were present in the crypt base in $\mathrm{H} \& \mathrm{E}$ (figure 1) or Ki67 stained tissue, or with haematoxylin counterstaining of in situ slides. The mitotic count per crypt is illustrated in figure 2C. The mean (range) of mitotic count was 5.2 (3.7-6.5) during infancy, decreased to 3.1 (2.0-3.5) during childhood and was 1.5 (1.2-2.0) during 
Table 1 Effect of 5 days of recombinant Dickkopf (100 ng subcutaneously) treatment on the small intestine of 16-dayold rats

\begin{tabular}{lcll}
\hline Group & $\begin{array}{l}\text { Crypt } \\
\text { fission }\end{array}$ & $\begin{array}{l}\text { Mitotic count/ } \\
\text { crypt section }\end{array}$ & $\begin{array}{l}\text { LGR5 count/ } \\
\text { crypt section }\end{array}$ \\
\hline $\begin{array}{l}\text { Control } \\
\text { Dickkopf- } \\
\text { treated }\end{array}$ & $3(2.0)^{\star}$ & $2.0(0.4) \dagger$ & $2.8(0.4)^{\star}$ \\
\hline
\end{tabular}

Data are given as mean (SD) of five animals in each group.

${ }^{*} \mathrm{P}<0.0001$.

$\dagger$ Not significant.

LGR5, leucine-rich repeat-containing G-protein coupled receptors.

teenage years. We previously determined the mean (range) value for 39 adults as $2.4(0.7-3.8)$. Apoptotic body count is illustrated in figure 2D. Apoptotic count was zero until approximately 3 years, and then increased and stabilised during childhood to 1.9 apoptotic bodies per whole crypt.

\section{Dickkopf treatment and LGR5+ stem cells and crypt fission in the rat}

Dickkopf reduced LGR5+ stem cells and crypt fission to $45 \%$ and $28 \%$, respectively, of control values, but did not affect mitotic count per crypt (table 1). This shows the dependence of crypt fission on LGR5+ cells.

\section{DISCUSSION}

This study found elevated crypt fission and expanded LGR5+ intestinalstem cells in humans and rats during infancy (figure 2). Crypt fission declined after 3 years of age in humans, but the number of LGR5+ cells remained elevated during childhood until at least early teenage years but were low in adults. Crypt cell apoptosis was zero during infancy but increased after 3 years of age. Possibly, increased crypt stem cell apoptosis lowered LGR5+ stem cells at an age when crypt fission had started to decline. Crypt fission occurs earlier in humans than in rats, as it begins in fetal life rather than perinatally as in the rat. ${ }^{16}$ We speculate that LGR5+ numbers are regulated not only by proliferation through crypt fission, but also by apoptosis.

Dehmer $e t a \rho^{\natural}$ found a similar peak of crypt fission in 14-day-old infant mice, a progressive increase in crypts per intestinal circumference, expansion of stem cells by flow cytometry, and a peak of tissue LGR5 RNA, which is an exclusive stem cell marker. However, they unexpectedly found no increase in stem cells per crypt in GFPLGR5 expressing transgenic mice. In contrast, we found LGR5+ intestinalstem cells were elevated in rats 7 and 14 days old and in humans from infancy until teenage years. We had the advantage of an extended time course. In addition, our technique of in situ hybridisation was a direct and specific physiological measure of stem cells. In rats, intestinal stem cells decreased much earlier in ontogeny than humans (figure 3). Stem cells were still elevated until mid-teenage years in humans (figure 3).
This shows the importance of studying humans, as stages or duration of ontogeny may differ between animals and humans.

Our microdissection technique was five fold more sensitive in evaluating crypt fission than assessment by histological branching, at least in humans in whom biopsy size may be limited. It changed the appreciation of crypt fission from an uncommon to a common process, as can be gleamed by comparing the peak values in the three infants of $27.3 \%$ by microdissection and $5.1 \%$ by histological branching. The reason for the discrepancy is that microdissection expresses crypt fission as percentage of bifid whole crypts over 100 whole crypts. Each crypt is typically $50 \mu \mathrm{m}$ in diameter as compared with the $5 \mu \mathrm{m}$ thickness of histological sections, with one $(\mathrm{z})$ dimension and other two $(\mathrm{x}, \mathrm{y})$ higher dimensions depending on whether the histological plane of section was glancing or not. Moreover, it is more accurate as the sample size is larger at 100 or more, as each villus has 6 crypts attached in the case of humans and 3-15 crypts per villus for rats.

Elevated LGR5+ stem cells were present with crypt fission during infancy. However, proliferation of stem cells was not immediately apparent. The cell cycle time in mouse intestine for stem cells is 21 hours, and 12 hours for transit amplifying cells. ${ }^{19}$ Thus, stem cells are slowly but continuously proliferating. A 'cloak of invisibility' hides the expansion of stem cells due to their slow proliferation (figure 1). These cells lose their LGR5 marker and form crypts with differentiated cells. Thus, the peak of LGR5+ cells during infancy promotes intestinal growth and drives crypt fission with their differentiated progeny that lose or have lost their 'stemness'.

Initially doubling of stem cells per crypt was suggested as the initiator of crypt fission. ${ }^{26}{ }^{27}$ However, this was not observed by Dehmer et al in mice and was not present in the current study. Later Langlands $e t a l^{28}$ described clustering of Paneth cells around an intestinal stem cell. This was observed in the current study. A cluster of Paneth cells is seen with a mitotic figure of a crypt base culumnar (CBC) at the leading edge of the fissure (figure 1B). Pin et $a l^{29}$ further described how fission is initiated by a weakness of the base of the crypt at the stem cell site from the viscoelastic forces of the stronger adjacent Paneth cells.

Crypt fission was dependent on LGR5+ cells in the rat, as Dickkopf treatment reduced both LGR5+ cells and crypt fission. The present work extends the previous studies, ${ }^{34-36}$ which showed elevated Wnt signalling at the base of crypts in rats and humans. Those studies did not examine LGR5+ cells. The present study extended those studies to LGR5 + stem cells and showed that Dickkopf reduced LGR5+ stem cells to $45 \%$, and as a consequence crypt fission was reduced to $29 \%$ of control values. The study also showed dependence of crypt fission on LGR5+ stem cells. Therefore, Wnt- $\beta$-catenin 
signalling promotes crypt fission by promoting expansion of LGR5+ cells.

In contrast, Kabiri et $a l^{37}$ found that Wnt signalling blockade in adult mice led to a brief period of proliferation of stem cells with C59 PORCN inhibitor in mice. Presumably this proliferation led to increased stem cells, although the numbers were not evaluated, only proliferating cells were counted and apoptosis was not evaluated. This contrasts with our finding of decreased stem cells after Wnt blockade with Dickkopf. We cannot explain this discrepancy other than to comment that inhibition with Dickkopf is very selective but less severe than with PORCN inhibitors. The human has similar features of high Wnt- $\beta$-catenin signalling during infancy, ${ }^{36}$ a peak of crypt fission during infancy, ${ }^{8}$ and an expanded population of LGR5+ stem cells (figure 3). Dickkopf treatment did not affect the mitotic count per crypt, which must be determined by the higher proliferation of the progeny of LGR5+ cells in the transit amplifying zone. These progeny which have lost their LGR5 + marker must be under different control. ${ }^{37}$

There is an inherent difficulty with analysing biopsies from humans rather than animals, as all the subjects had an independent medical reason for endoscopy, which limited the number of subjects available. We ensured that no duodenal disease was present by recruiting only those with reflux oesophagitis, which does not affect the duodenum. As well, the number and size of the biopsy may limit the number of determinations that can be performed. This is why we also studied the postnatal growth of the small intestine in rats. The sample size was greater in rats, and peaks of crypt fission and LGR5+ cells coincided during infancy. Our microdissection technique was reproducible within $\sim 10 \%$ for crypt fission. It is superior to histological assessment as it assesses the whole crypt. Our data are consistent with that of laboratory rats, such as a peak of crypt fission and of Wnt- $\beta$-catenin signalling during infancy. ${ }^{64-36}$

In summary, crypt fission peaked during infancy in both humans and rats, and this coincided with elevated LGR5+ stem cells. We confirmed the in vitro and mouse evidence that Paneth cells cluster around a CBC to promote expansion of stem cells and their progeny with crypt fission. The elevated LGR5+ cells decreased earlier in ontogeny at day 21 in rats, but remained elevated in humans until mid-teenage years. Blockade of Wnt- $\beta$-catenin signalling in rat pups by Dickkopf, a specific Wnt inhibitor, reduced LGR5+ stem cells and consequently prevented crypt fission.

Acknowledgements We thank the endoscopy and theatre nursing staff at the Women's and Children's Hospital who participated with the biopsy collection; Ms J Hawkes who helped with the initial form preparation and submission to the Human Ethics Committee; Dr J Couper and Ms S Wade at the Department of Histopathology, SA Pathology, The Queen Elizabeth Hospital, who arranged for embedding and H\&E staining of the specimens; Ms W Uylaki, Department of Gastroenterology, Basil Hetzel Institute, for help with laboratory orders and procedures; and Ms S Edwards for her help in statistical analysis. We acknowledge the help and are grateful to Dr I Lidums and other consultant staff of The Queen Elizabeth Hospital and the Basil Hetzel Institute for Translational Health Research.
Contributors ZMD conducted the experimental work, data analysis and drafted the manuscript. AGC helped with data analysis and drafting of the manuscript. PDH collected the patient biopsies and helped in drafting of the manuscript. GSH helped analyse the data and in drafting the manuscript.

Funding This study was funded by the Private Practice Fund of the Department of Gastroenterology and Hepatology, The Queen Elizabeth Hospital.

Competing interests None declared.

Patient consent for publication Not required.

Ethics approval This study was approved by the Human Ethics Committee of the Women's and Children's Health Service, North Adelaide and the Animal Ethics Committee of The University of Adelaide, South Australia, Australia. Ethics approval for adults from previous research studies was obtained from the Human Research Ethics Committee of The Queen Elizabeth Hospital.

Provenance and peer review Not commissioned; externally peer reviewed.

Data availability statement Data are available upon reasonable request. Individual subjects will not be identified unless approved by the human ethics committees.

Open access This is an open access article distributed in accordance with the Creative Commons Attribution Non Commercial (CC BY-NC 4.0) license, which permits others to distribute, remix, adapt, build upon this work non-commercially, and license their derivative works on different terms, provided the original work is properly cited, appropriate credit is given, any changes made indicated, and the use is non-commercial. See: http://creativecommons.org/licenses/by-nc/4.0/.

ORCID iD

Zenab Mustansir Dudhwala http://orcid.org/0000-0001-6524-8945

\section{REFERENCES}

1 Cheng $\mathrm{H}$, Bjerknes $\mathrm{M}$. Whole population cell kinetics and postnatal development of the mouse intestinal epithelium. Anat Rec 1985;211:420-6.

2 Cheng $\mathrm{H}$, Leblond CP, Origin LCP. Origin, differentiation and renewal of the four main epithelial cell types in the mouse small intestine. V. Unitarian theory of the origin of the four epithelial cell types. $\mathrm{Am} \mathrm{J}$ Anat 1974:141:537-61.

3 Dehmer JJ, Garrison AP, Speck KE, et al. Expansion of intestinal epithelial stem cells during murine development. PLoS One 2011;6:e27070.

4 Clarke RM. The effect of growth and of fasting on the number of villi and crypts in the small intestine of the albino rat. $J$ Anat 1972;112:27-33.

5 St Clair WH, Osborne JW. Crypt fission and crypt number in the small and large bowel of postnatal rats. Cell Tissue Kinet 1985;18:255-62.

6 Cummins AG, Jones BJ, Thompson FM. Postnatal epithelial growth of the small intestine in the rat occurs by both crypt fission and crypt hyperplasia. Dig Dis Sci 2006;51:718-23.

7 Słupecka M, Woliński J, Pierzynowski SG. Crypt fission contributes to postnatal epithelial growth of the small intestine in pigs. Livest Sci 2010;133:34-7.

8 Cummins AG, Catto-Smith AG, Cameron DJ, et al. Crypt fission peaks early during infancy and crypt hyperplasia broadly peaks during infancy and childhood in the small intestine of humans. $J$ Pediatr Gastroenterol Nutr 2008;47:153-7.

9 Wasan HS, Park HS, Liu KC, et al. APC in the regulation of intestinal crypt fission. J Pathol 1998;185:246-55.

10 Dekaney CM, Gulati AS, Garrison AP, et al. Regeneration of intestina stem/progenitor cells following doxorubicin treatment of mice. Am J Physiol Gastrointest Liver Physiol 2009;297:G461-70.

11 Park HS, Goodlad RA, Wright NA. Crypt fission in the small intestine and colon. A mechanism for the emergence of G6PD locus-mutated crypts after treatment with mutagens. Am J Pathol 1995:147:1416-27.

12 Cairnie AB, Millen BH. Fission of crypts in the small intestine of the irradiated mouse. Cell Tissue Kinet 1975;8:189-96.

13 Dekaney CM, Fong JJ, Rigby RJ, et al. Expansion of intestinal stem cells associated with long-term adaptation following ileocecal resection in mice. Am J Physiol Gastrointest Liver Physiol 2007;293:G1013-22.

14 Rowland KJ, Choi PM, Warner BW. The role of growth factors in intestinal regeneration and repair in necrotizing enterocolitis. Semin Pediatr Surg 2013;22:101-11. 
15 Drozdowski L, Thomson ABR. Intestinal hormones and growth factors: effects on the small intestine. World J Gastroenterol 2009;15:385-406.

16 Cummins AG, Thompson FM. Effect of breast milk and weaning on epithelial growth of the small intestine in humans. Gut 2002;51:748-54.

17 Clevers $\mathrm{H}$. The intestinal crypt, a prototype stem cell compartment. Cell 2013;154:274-84.

18 Sato T, van Es JH, Snippert HJ, et al. Paneth cells constitute the niche for LGR5 stem cells in intestinal crypts. Nature 2011;469:415-8.

19 Kabiri Z, Greicius G, Madan B, et al. Stroma provides an intestinal stem cell niche in the absence of epithelial Wnts. Development 2014;141:2206-15.

20 Barker N, van Es JH, Kuipers J, et al. Identification of stem cells in small intestine and colon by marker gene LGR5. Nature 2007;449:1003-7.

21 Pinto D, Gregorieff A, Begthel H, et al. Canonical Wnt signals are essential for homeostasis of the intestinal epithelium. Genes Dev 2003:17:1709-13.

22 Gregorieff A, Pinto D, Begthel H, et al. Expression pattern of Wnt signaling components in the adult intestine. Gastroenterology 2005;129:626-38.

23 Flanagan DJ, Phesse TJ, Barker N, et al. Frizzled7 functions as a Wnt receptor in intestinal epithelial Lgr5(+) stem cells. Stem Cell Reports 2015;4:759-67.

24 Greicius G, Kabiri Z, Sigmundsson K, et al. PDGFR $\alpha^{+}$pericryptal stromal cells are the critical source of Wnts and RSPO3 for murine intestinal stem cells in vivo. Proc Natl Acad Sci U S A 2018;115:E3173-81.

25 Schepers AG, Vries R, van den Born M, et al. Lgr5 intestinal stem cells have high telomerase activity and randomly segregate their chromosomes. Embo J 2011;30:1104-9.

26 Totafurno J, Bjerknes M, Cheng $\mathrm{H}$. The crypt cycle. crypt and villus production in the adult intestinal epithelium. Biophys $J$ 1987;52:279-94.
27 Loeffler M, Grossmann B. A stochastic branching model with formation of subunits applied to the growth of intestinal crypts. $J$ Theor Biol 1991;150:175-91.

28 Langlands AJ, Almet AA, Appleton PL, et al. Paneth cell-rich regions separated by a cluster of Lgr5+ cells initiate crypt fission in the intestinal stem cell niche. PLoS Biol 2016;14:e1002491.

29 Pin C, Parker A, Gunning AP, et al. An individual based computational model of intestinal crypt fission and its application to predicting unrestrictive growth of the intestinal epithelium. Integr Biol 2015;7:213-28.

30 Ferguson A, Sutherland A, MacDonald TT, et al. Technique for microdissection and measurement in biopsies of human small intestine. J Clin Pathol 1977;30:1068-73.

31 Goodlad RA WT, Lenton W. Microdissection-based techniques for the determination of cell proliferation in gastrointestinal epithelium:application to animal and human studies. In: Cell biology: a laboratory handbook. New York: Celis JE Academic Press, 1994: 205-16.

32 Cummins AG, LaBrooy JT, Stanley DP, et al. Quantitative histological study of enteropathy associated with HIV infection. Gut 1990;31:317-21.

33 Cummins AG, Alexander BG, Chung A, et al. Morphometric evaluation of duodenal biopsies in celiac disease. Am J Gastroenterol 2011;106:145-50.

34 Fauser JK, Donato RP, Woenig JA, et al. Wnt blockade with dickkopf reduces intestinal crypt fission and intestinal growth in infant rats. $J$ Pediatr Gastroenterol Nutr 2012;55:26-31.

35 Camac KS, Thompson FM, Cummins AG. Activation of beta-catenin in the stem cell region of crypts during growth of the small intestine in infant rats. Dig Dis Sci 2007;52:1242-6.

36 Dudhwala ZM, Drew PA, Howarth GS, et al. Active $\beta$-catenin signaling in the small intestine of humans during infancy. Dig Dis Sci 2019;64:76-83.

37 Kabiri Z, Greicius G, Zaribafzadeh H, et al. Wnt signaling suppresses MAPK-driven proliferation of intestinal stem cells. J Clin Invest 2018;128:3806-12. 